\title{
APPLICATION OF SUB-CRITICAL WATER FOR RECOVERY OF TIN AND GLASS SUBSTRATES FROM LCD PANEL E-WASTE
}

\author{
Hiroyuki Yoshida ${ }^{1,2}$, Shamsul Izhar ${ }^{1,2 \star}$, Eiichiro Nishio ${ }^{3}$, Yasuhiko Utsumi ${ }^{3}$, Nobuaki \\ Kakimori ${ }^{3}$ and Salak Asghari Feridoun ${ }^{2}$ \\ ${ }^{1}$ Department of Chemical and Environmental Engineering, Faculty of Engineering, Universiti Putra Malaysia, 43400 UPM Serdang, \\ Selangor, Malaysia \\ ${ }^{2}$ Ecology Research Center, Research Organization for the 21st Century, Osaka Prefecture University, 1-1 Gakuen-Cho, Naka-ku, Sakai, \\ Osaka 599-8570, Japan \\ ${ }^{3}$ Environment Research and Development Center, Environmental Protection Group, Sharp Corporation, 1 Takumi-Cho, Sakai-ku, Sakai, \\ Osaka 590-8522, Japan
}

Article Info:
Received:
12 July 2018
Revised:
19 September 2018
Accepted:
14 November 2018
Available online:
22 November 2018
Keywords:
Sub-critical water
LCD panel waste
Tin recovery
CF glass
TFT glass

\section{ABSTRACT}

Tin and transparent glass substrate were efficiently recovered from color filter (CF) and thin-film transistor (TFT) glasses in LCD panel wastes using sub-critical water (sub-CW) at various treatment temperatures and reaction time. Treatment for $5 \mathrm{~min}$ using sub-CW added with $\mathrm{NaOH}$ resulted in a $95 \%$ recovery of tin from CF and TFT glasses. The tin oxide did not liquify in the liquid phase instead stayed in the organic multi-layers, which exfoliated together from the CF glass and TFT glass. This is a huge advantage because the organic multi-layers were readily separated by sub-CW and tin was recovered by filtration with ease. Transparent and clean glass was also recovered from LCD panel waste. The amount of tin oxide recovered depended on the sub-CW reaction temperature, reaction time and $\mathrm{NaOH}$ concentration. Treatment of smaller CF glass improved the recovery of tin. With this advance, we have showed that sub-CW method is technically feasible for tin oxide recovery in LCD waste.

\section{INTRODUCTION}

Liquid crystal display (LCD) panel consists of layers of polymer, thin-film transistor (TFT), liquid crystal, and color filter (CF) substrates. These layers contain complex circuits, electrodes, multiple organic layers and glass substrates as shown in Figure 1. The electrode used in LCDs comprises of indium tin oxide (ITO), a mixture of $90 \mathrm{wt} \%$ indium (III) oxide $\left(\mathrm{In}_{2} \mathrm{O}_{3}\right)$ and $10 \mathrm{wt} \%$ tin (IV) oxide $\left(\mathrm{SnO}_{2}\right)$ (Alfatanzani et al., 2003). Thus, many studies have been carried out to recover valuable material from scrap LCD screens. Most studies have concentrated on hydrometallurgical methods (Hsieh et al., 2009) such as acid dissolution or acid leaching (Li et al., 2009; Li et al., 2011; Gabriel et al., 2017a; Gabriel et al., 2017b), solvent extraction (Fortes et al., 2003; Honma and Muratani, 2005) and chlorination (Park et al., 2009) methods. However, those studies require the need for wastewater treatment after recovering the metals. Furthermore, clean glass cannot be recovered because only a part of the metal is extracted while multilayers of polymer films, TFT, CF and liquid crystals are still stuck on the glass surface.

In the present work, sub-critical water (sub-CW) was employed. Sub-critical water has been developed for sol- id waste resources recovery and is gaining interest due to its potential as solvent and catalyst for organic reaction. This practice is based on the use of water as medium, at temperatures between its boiling point $\left(100^{\circ} \mathrm{C}\right)$ and critical point $\left(374^{\circ} \mathrm{C}\right)$ and at pressures higher than or equal to the pressure of saturated vapor pressure. At sub-critical conditions, the dielectric constant of water decreases, thereby lowering its polarity as depicted in Figure 2. Secondly, the magnitude of ionic product of water increases three orders around $250^{\circ} \mathrm{C}$ compared to room temperature. This will facilitate the dissociation of water making sub-CW advantageous for hydrolysis and decomposition of organic compounds including polymeric materials. Only a few papers have been published for metal recovery from multilayer films using sub-CW. Pure aluminum foil from waste composite laminates by decomposing plastic films by sub-CW hydrolysis reaction (Kulkarni et al., 2011). The plastics were also recovered as monomers.

Previously, a study revealed that $90 \%$ of indium was recovered from CF glass but only less than $7 \%$ indium from TFT glass (Yoshida et al., 2014). However, adding alkali improved the process where indium was totally removed and recovered from CF and TFT glass (Yoshida 


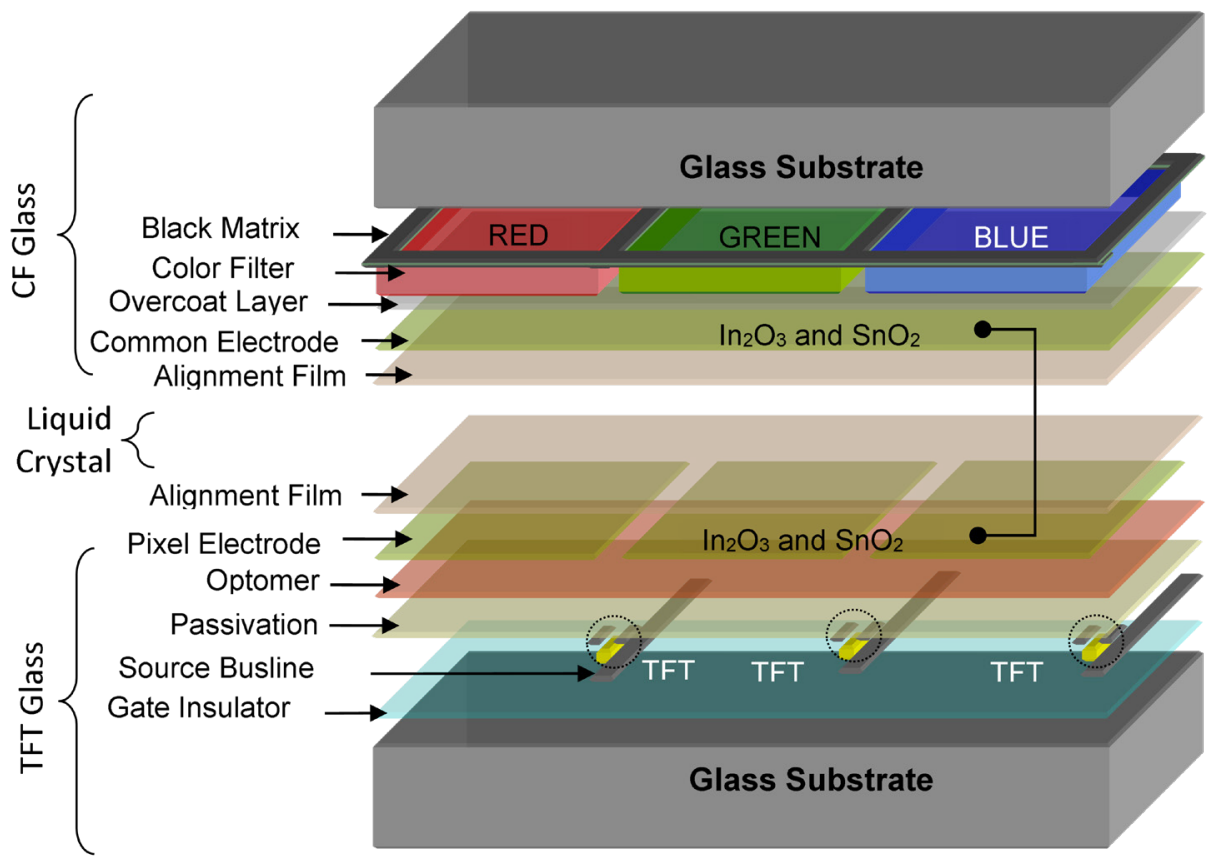

FIGURE 1: Detail cross section layout of a single pixel in a common liquid crystal display panel.

et al., 2015). However, the recoveries of other crucial elements, such as $\mathrm{SnO}_{2}$ and high-quality LCD glass substrate was not considered. Thus, in the present work, we investigated tin and glass substrate recovery using sub-CW. In addition, the recovery of clean and transparent glass was carried out by changing the sample sizes before sub-CW treatment.

\section{MATERIALS AND EXPERIMENTAL PROCE- DURE}

\subsection{Material preparation and sub-critical water treat- ment}

Preparation of raw material and sub-CW treatment were referred to Yoshida et al (2015). The waste LCD panel was a 40-inch TFT type (Sharp Corp.), composed of a polarizer, liquid crystals and arrangement of TFT and CF glasses. The polarizing films on the outer sides of the LCD were stripped off and separated into CF glass and TFT array by cutting the panel edge using a glass cutter. Liquid crystals on both glass surfaces were washed away by acetone. Each glass was crushed into $5-10 \mathrm{~mm}$ size, small enough to fit the reactor. The reactor as shown in Figure 3 was a stainless-steel tube with end-caps (Swagelok) were fitted to both ends of the tube $(16 \mathrm{~mm}$ internal diameter, $150 \mathrm{~mm}$ length). Pure water or $\mathrm{NaOH}$ aqueous solution with volume approximately $20 \mathrm{~mL}$ together with $6 \mathrm{~g}$ of either CF glass or TFT glass was filled into the reactor. The air in the reactor was replaced with argon gas before the reactor was sealed and weighed.

For the sub-CW treatment, the reactor was immersed quickly in a preheated molten salt bath (Tomasu Kagaku, Celsius 600) at a desired temperature. After the desired time was reached, the tube was taken out and immediately cooled at room temperature. The pressure inside the reactor was the saturated vapor pressure of water at the subsequent reaction temperature. The reaction time was defined as the time from immersing the reactor into the salt bath until before immediate cooling. The sample was then transferred from the tube to a beaker. The solid residues (substrate glass) were separated from the aqueous phase by means of vacuum filtration through a $1 \mu \mathrm{m}$ pore-sized membrane filter (Advantec, cellulose acetate). The filters were dried at room temperature and weigh.

\subsection{Measurement and analysis}

After sub-CW treatment, concentration of metal in each medium was determined. Tin was extracted using $7 \%$ hydrochloric acid solution from the remaining glass and membrane filter according to equation (1).

$\mathrm{SnO}_{2}+2 \mathrm{HCl} \rightarrow \mathrm{SnCl}_{4}+\mathrm{H}_{2} \mathrm{O}$

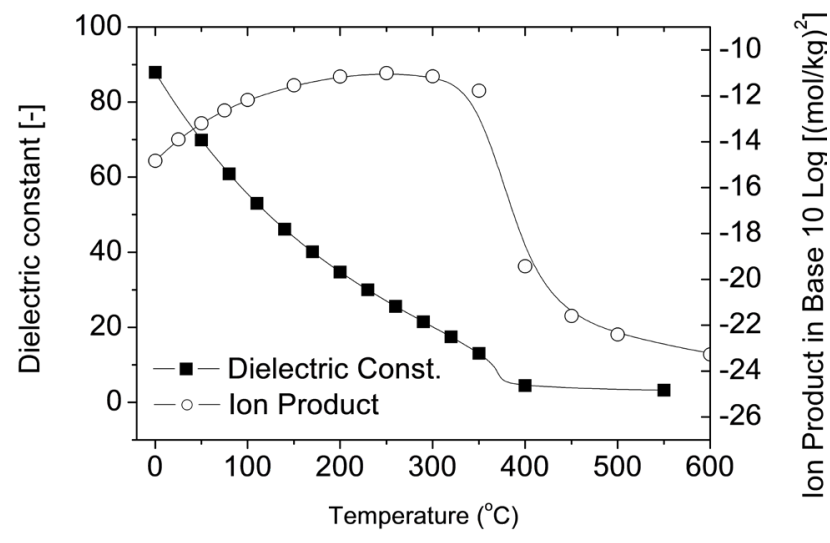

FIGURE 2: Dielectric constant and ionic products of water at sub-critical and supercritical state (Wolfgang and Kretzschmar, 2008). 

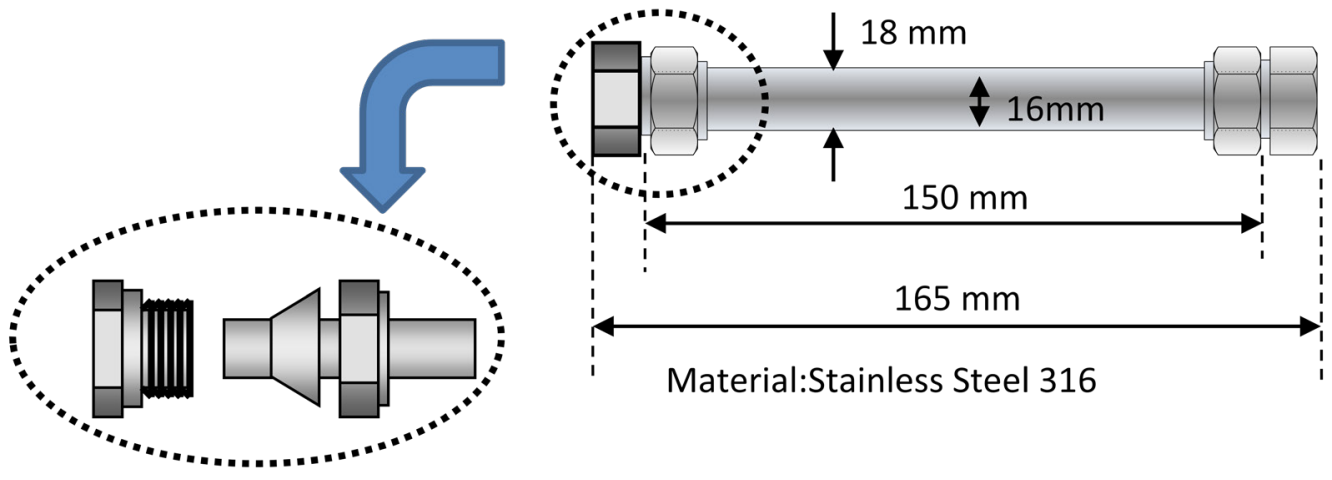

FIGURE 3: Layout of the reactor used for subcritical water treatment.

The tin concentrations, defined as mass of tin for every $\mathrm{kg}$ of LCD glass [mg/kg-LCD] in the solution extracted from the remaining glass substrate $\left(W_{g}\right)$, filter $\left(W_{f}\right)$ and liquid-phase $\left(W_{1}\right)$ were measured using a plasma atomic emission spectroscopy ICP (Shimadzu, ICPE-9000). The mass balance of fresh tin (Winit) before the reaction and after the reaction $\left(W_{g}, W_{f}\right.$ and $\left.W_{l}\right)$ was verified. The recovery of tin $\left(\eta_{S n}\right)$ was defined by the amount of tin that was filtered $\left(W_{f}\right)$ to the amount of tin in the fresh $\operatorname{LCD}\left(W_{\text {init }}\right)$ :

$\eta_{\text {Sn }}=\frac{W_{f}}{W_{\text {init }}} \times 100$

\section{RESULTS AND DISCUSSION}

\subsection{The concentrations of tin on CF and TFT glasses before sub-CW reaction}

To evaluate the amount of tin recovery, the total amount of tin on each fresh CF and TFT glasses were determined by extracting tin using $7 \%$ hydrochloric acid aqueous solution. Tin quantity in fresh CF glass and TFT glass $\left(W_{\text {init }}\right)$ were 36 and $28 \mathrm{mg} / \mathrm{kg}-\mathrm{LCD}$, respectively. The tin in TFT glass is $80 \%$ of the CF glass due to the sensitivity of the TFTs towards backlight illumination during application (Lee et al., 2008).

\subsection{Sub-CW reaction in CF and TFT glasses (without $\mathrm{NaOH})$}

TFT and CF glasses were treated by sub-CW without

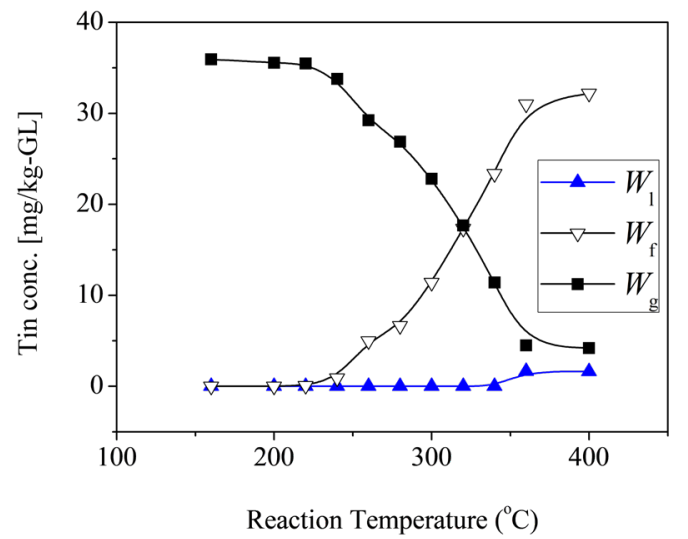

FIGURE 4: Tin distribution in filter $\left(W_{f}\right)$, liquid phase $\left(W_{f}\right)$ and glass $\left(W_{g}\right)$ after sub-CW treatment of CF glass for 5 min reaction time at various temperatures.
$\mathrm{NaOH}$ for 5 min reaction time at different reaction temperatures. The amounts of tin dissolved in the liquid-phase $\left(W_{1}\right)$, in the organic multi-layers on the membrane filter $\left(W_{f}\right)$ and in the residues on the glass surface $\left(W_{g}\right)$ after the reaction was detected by the same method as the untreated fresh TFT and CF glasses as mentioned is section 3.1. Figure 4 shows the results from CF glass treated with sub-critical water for 5 min reaction time at various temperatures. Tin was not detected in the liquid-phase $\left(W_{1}\right)$ when reaction temperature was lower than $360^{\circ} \mathrm{C}$. $W_{g}$ reduced steadily with increasing reaction temperature beginning from $220^{\circ} \mathrm{C}$ to $360^{\circ} \mathrm{C}$. At supercritical state $\left(400^{\circ} \mathrm{C}\right), W_{g}$ reduced to $4 \mathrm{mg} / \mathrm{kg}-\mathrm{LCD}$. Identically, $W_{f}$ showed the opposite trend to $W_{g}$ where $W_{f}$ increased with increasing treatment temperature. At supercritical state $\left(400^{\circ} \mathrm{C}\right), W_{f}$ was $31 \mathrm{mg} / \mathrm{kg}$-LCD. Higher treatment temperature resulted in a more tin exfoliation from the LCD surface, although small amount of tin was detected in the liquid phase $\left(W_{l}\right)$ when temperature was higher than $360^{\circ} \mathrm{C}$. This is because the exfoliated multilayer organics, in which tin oxide was sandwiched, decomposed at very high temperature and tin oxide exposed to sub-CW.

Figure 5 demonstrates the results in TFT glass treated with sub-critical water for 5 min reaction time at various temperatures. Tin was not discovered at all in $W_{\text {l }}$. Treatment below $260^{\circ} \mathrm{C}$ and above $340^{\circ} \mathrm{C}$ showed no drop of $W_{g}$

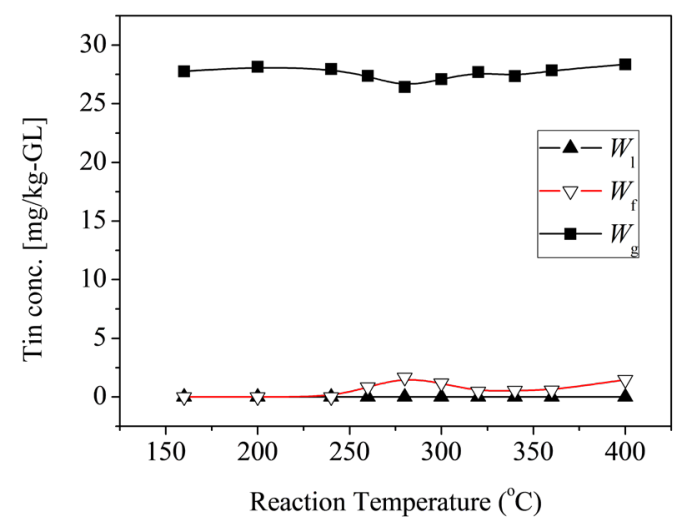

FIGURE 5: Tin distribution in filter $\left(W_{f}\right)$, liquid phase $\left(W_{t}\right)$ and glass $\left(W_{g}\right)$ after sub-CW treatment of TFT glass without $\mathrm{NaOH}$ for 5 min reaction time at various temperatures. 
suggesting no tin was removed from TFT glass. At around $280^{\circ} \mathrm{C}, W_{g}$ was $26 \mathrm{mg} / \mathrm{kg}-\mathrm{LCD}$, demonstrating small amount of tin was removed. This could be attributed to hydrolysis, because at this temperature the ionic product is high as indicated in Figure 2, suggesting hydrolysis is active. At $400^{\circ} \mathrm{C}, W_{g}$ was $28 \mathrm{mg} / \mathrm{kg}-\mathrm{LCD}$ indicating greater part of the tin remained on TFT glass. These results suggest that multilayer organics which sandwiched tin oxide were difficult to be exfoliated by sub-CW and even by super critical water. TFT layers are usually covered with a thin alignment layer ( 80-100 nm thickness), with a function to insulate the optomer layer and to protect the passivation layers (Lee et al., 2008). The optomer film shown in Figure 1 is an organic mixture consisting of mostly diethylene glycol methyl eth$y l$ ether and acrylic resin. The passivation layer wrapping the drain and source terminals are made of silicon nitride $\left(\mathrm{SiN}_{\mathrm{x}}\right)$. This implied that the optomer and passivation layers on the TFT glass were insufficiently decomposed by treatment with only sub-CW and supercritical water. However, it is worth noting that $W$, was near zero in every circumstance. Consequently, the results in Figures 4 and 5 showed that tin did not dissolve in the liquid-phase but was appended with the organic multilayers and were removed together from the CF and TFT glasses.

\subsection{Tin recovery from CF and TFT glasses with Sub- $\mathrm{CW}$ added with $\mathrm{NaOH}$}

To overcome the insufficient decomposition, $\mathrm{NaOH}$ was added in sub-CW. Figure 6 illustrates the effect of $\mathrm{NaOH}$ concentration in Sub-CW on tin recovery $\eta_{\mathrm{Sn}}$ from TFT and CF glasses. The reaction time was $5 \mathrm{~min}$. For TFT glass, at $220^{\circ} \mathrm{C}$, almost no tin was recovered when treatment was performed using less than $0.03 \mathrm{M} \mathrm{NaOH}$. However, when treated with concentrations above $0.1 \mathrm{M}$, the amount of tin recovered was more than $80 \%$ for TFT glass. This suggests that concentration of $\mathrm{NaOH}$ in sub-CW is important for decomposing the organic multilayers in $\mathrm{CF}$ and TFT glasses.

In CF glass at $160^{\circ} \mathrm{C}$, a similar result with TFT glass at $220^{\circ} \mathrm{C}$ was observed. But maximum recovery was more than $90 \%$ when $\mathrm{NaOH}$ concentration was higher than 0.2 $\mathrm{M}$. Then a slightly higher reaction temperature $\left(180^{\circ} \mathrm{C}\right)$ for CF glass was examined. The recovery of tin increased substantially, and $90 \%$ tin recovery were obtained in $0.1 \mathrm{M}$ $\mathrm{NaOH}$ concentration.

Figure 7 demonstrates the effect of reaction temperature on the recovery of tin $\eta_{S n}$ by sub-CW treatment for 5 min with water-only and with $0.1 \mathrm{M} \mathrm{NaOH}$ added. For CF glass (Figure 7A), $\eta_{S n}$ with water-only treatment was found to be inactive below $240^{\circ} \mathrm{C}$. The $\eta_{S n}$ increased from none at $240^{\circ} \mathrm{C}$ to $80 \%$ at $360^{\circ} \mathrm{C}$. $\eta_{S n}$ remained $80 \%$ until $400^{\circ} \mathrm{C}$. These results exhibited that treatment temperature directly affects tin exfoliation from CF glass. However, when $0.1 \mathrm{M}$ $\mathrm{NaOH}$ was present, the tin recovery was $45 \%$ even at $100^{\circ} \mathrm{C}$. This suggests that hydrolysis process was probably active and had already occurred at water boiling temperature. The tin recovery increased to $95 \%$ at $160^{\circ} \mathrm{C}$ and remained about $90 \%$ at $360^{\circ} \mathrm{C}$. With the presence of $\mathrm{NaOH}, \mathrm{SiN}_{\mathrm{x}}$ from the passivation layer has dissolved into the liquid-phase as a result of the exfoliation of the organic multi-layers. Addi- tion of $\mathrm{NaOH}$ probably caused corrosion of the substrate glass in $\mathrm{NaOH}$ environment causing the formation of sodium silicate. This showed the significant effect of the presence of $\mathrm{NaOH}$ to the tin recovery from CF glass.

In Figure 7B, for TFT glass treated by sub-CW without $\mathrm{NaOH}, \eta_{S n}$ gradually increased from none at $240^{\circ} \mathrm{C}$ to $6 \%$ peak at $280^{\circ} \mathrm{C}$. However, when $0.1 \mathrm{M} \mathrm{NaOH}$ existed in sub$\mathrm{CW}, \eta_{S n}$ increased drastically with reaction temperature. When the temperature was higher than $160^{\circ} \mathrm{C}, \eta_{S n}$ increased to $95 \%$ at $220^{\circ} \mathrm{C}$. The $\eta$ was around $93 \%$ between 220 and $340^{\circ} \mathrm{C}$. These results implied that the decomposition of the passivation and optomer layers on the TFT glass was enhanced significantly by the presence of $\mathrm{NaOH}$ in sub-CW. However, at $360^{\circ} \mathrm{C}$ the $\eta_{S n}$ slightly dropped to $70 \%$. A previous study by Yoshida et al., has shown that high content of $\mathrm{Si}$ ion in $W$, caused of the formation of sodium silicate at

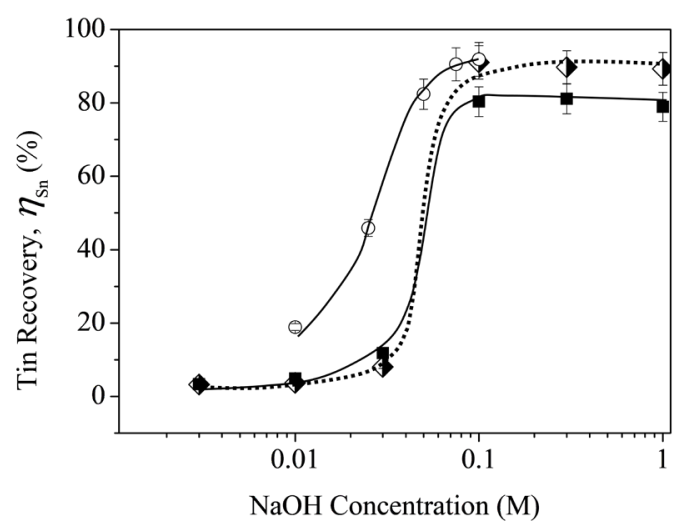

FIGURE 6: Effect of $\mathrm{NaOH}$ concentration in Sub-CW on the recovery of tin ( $5 \mathrm{~min}$ of reaction time). ( $\square$ ) CF glass treated at $160^{\circ} \mathrm{C}$, $(\triangle) \mathrm{CF}$ glass treated at $180^{\circ} \mathrm{C}$ and (a) TFT glass treated at $220^{\circ} \mathrm{C}$.

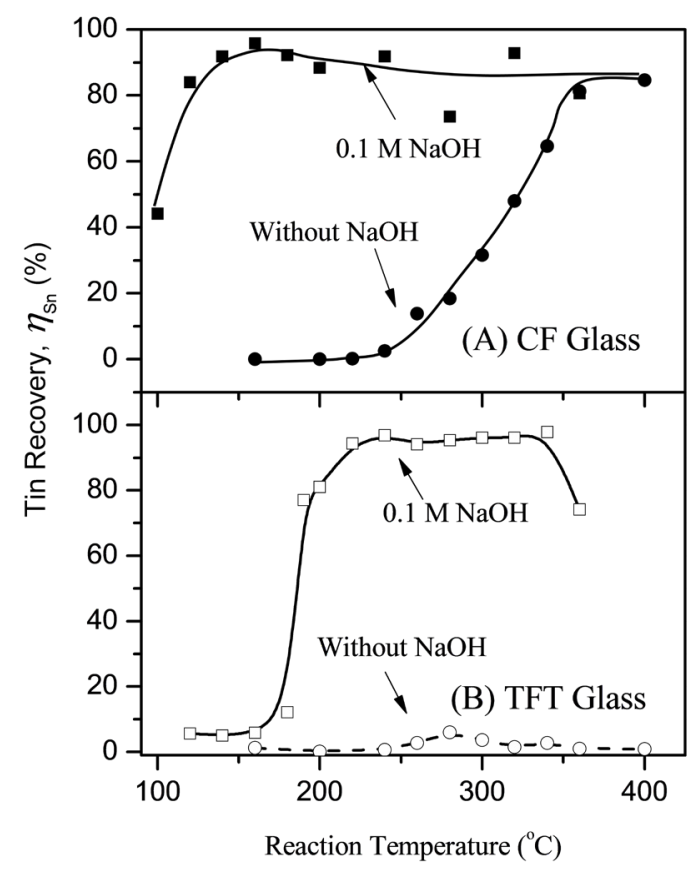

FIGURE 7: Effect of sub-CW reaction temperature on the recovery of tin $(\eta)$ with $0.1 \mathrm{~N} \mathrm{NaOH}$ added and without $\mathrm{NaOH}$ (reaction time was $5 \mathrm{~min})$. 
very high temperature. During ICP analysis of $W_{p}$, due to the adjacent wavelength of tin and silica, the high intensity of silica interfered with tin causing the appearance of tin in $W_{l}$. Thus, this resulted in the small reduction of $\eta_{S n}$.

Figure 8 illustrates the time course of the recovery of tin $\eta_{\mathrm{Sn}}$ from CF glass during sub-CW treatment with (a) $0.1 \mathrm{M}$ $\mathrm{NaOH}$ at $160^{\circ} \mathrm{C}$, (b) $0.05 \mathrm{M} \mathrm{NaOH}$ at $180^{\circ} \mathrm{C}$, and $0.1 \mathrm{M} \mathrm{NaOH}$ at $360^{\circ} \mathrm{C}$. The three curves were close to each other until 30 min. They showed the reactions were rapid because after only $5 \mathrm{~min}, \eta_{S n}$ immediately became $80-90 \%$. The reaction time of 5-15 min showed maximum recovery at $91-95 \%$. After $30 \mathrm{~min}$, curve (a) was close to curve (b) and $\eta_{S n}$ in both (a) and (b) slightly decreased with time. However, $\eta_{S n}$ in (c) decreased significantly with time. When reaction time was extended, the exfoliated multilayer organics that sandwiched $\mathrm{SnO}_{2}$ were decomposed in small amount for (a) $160^{\circ} \mathrm{C}$ and (b) $180^{\circ} \mathrm{C}$, but in large portion for (c) $360^{\circ} \mathrm{C}$. The drop of $\eta_{S n}$ at $360^{\circ} \mathrm{C}$ is probably due to the difficulty to discriminate the intensity of silica and tin when analyzing the ICP results.

Figure 8 illustrates also the tin recovery from TFT glass by treatment with $0.1 \mathrm{M} \mathrm{NaOH}$ at $220^{\circ} \mathrm{C}$. The $\eta_{S n}$ was $75 \%$ when treatment was performed for 2 min, but was maximum at $80 \%$ when treated for $5 \mathrm{~min}$. The $\eta_{S n}$ did not go above $80 \%$ when treated above 5 min. Thus, when the concentration of $\mathrm{NaOH}$ was $0.1 \mathrm{M}$ and reaction time was 5-15 min, maximum recovery of tin from CF and TFT glasses was attained. Most leaching using acid solution was able recover $89 \%$ to $99 \%$ of tin in the form of ITO as reviewed in the literature (Ueberschaar et al, 2017). The result in the present study using subcritical water showed a 80 to $95 \%$ recovery from CF and TFT glasses, which is comparable to the hydrometallurgical methods. Furthermore, only a short time of 5 min is required thus making subcritical water method a promising technology and excellent alternative to the hydrometallurgical method.

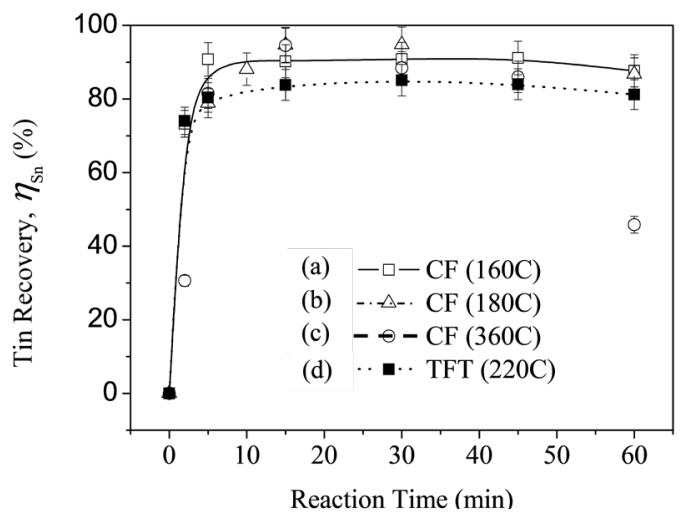

FIGURE 8: Time course of tin recovery from CF glass by sub-CW treatment at various reaction time: a) $0.1 \mathrm{M} \mathrm{NaOH}$ at $160^{\circ} \mathrm{C}$, (b) $0.05 \mathrm{M} \mathrm{NaOH}$ at $180^{\circ} \mathrm{C}$, (c) $0.1 \mathrm{M} \mathrm{NaOH}$ at $360^{\circ} \mathrm{C}$, and from TFT glass (d) $0.1 \mathrm{M} \mathrm{NaOH}$ at $220^{\circ} \mathrm{C}$.

\subsection{The effect of sizes of CF glass on sub-CW reac- tion}

Figure 9 illustrates the effect of glass size on the remaining color of $\mathrm{CF}$ glass after sub-CW treatment with $0.1 \mathrm{M} \mathrm{NaOH}$ for $5 \mathrm{~min}$ at $180^{\circ} \mathrm{C}$. The CF glass was cut using a glass cutter into about $20 \mathrm{~mm}$ and crushed to about 5 $\mathrm{mm}$ length. After the sub-CW treatment, the larger size glass still has color remained from color filter pigment. While the smaller sized glass became completely clear of any pigment color. This showed that smaller sized glass which consisted of large amount of surface area effected the removal of CF pigments. As for the large sized glass, the color remained at the middle of the glass surface, indicating that as the surfaces of the glasses adhered each other, sub-CW contacted slightly with the surface but probably penetrated through the side of the glasses adhered.

Table 1 indicates the recovery of tin from CF glass cut into $5-10 \mathrm{~mm}, 20 \mathrm{~mm}$ and crushed to $5 \mathrm{~mm}$ length. Treat-

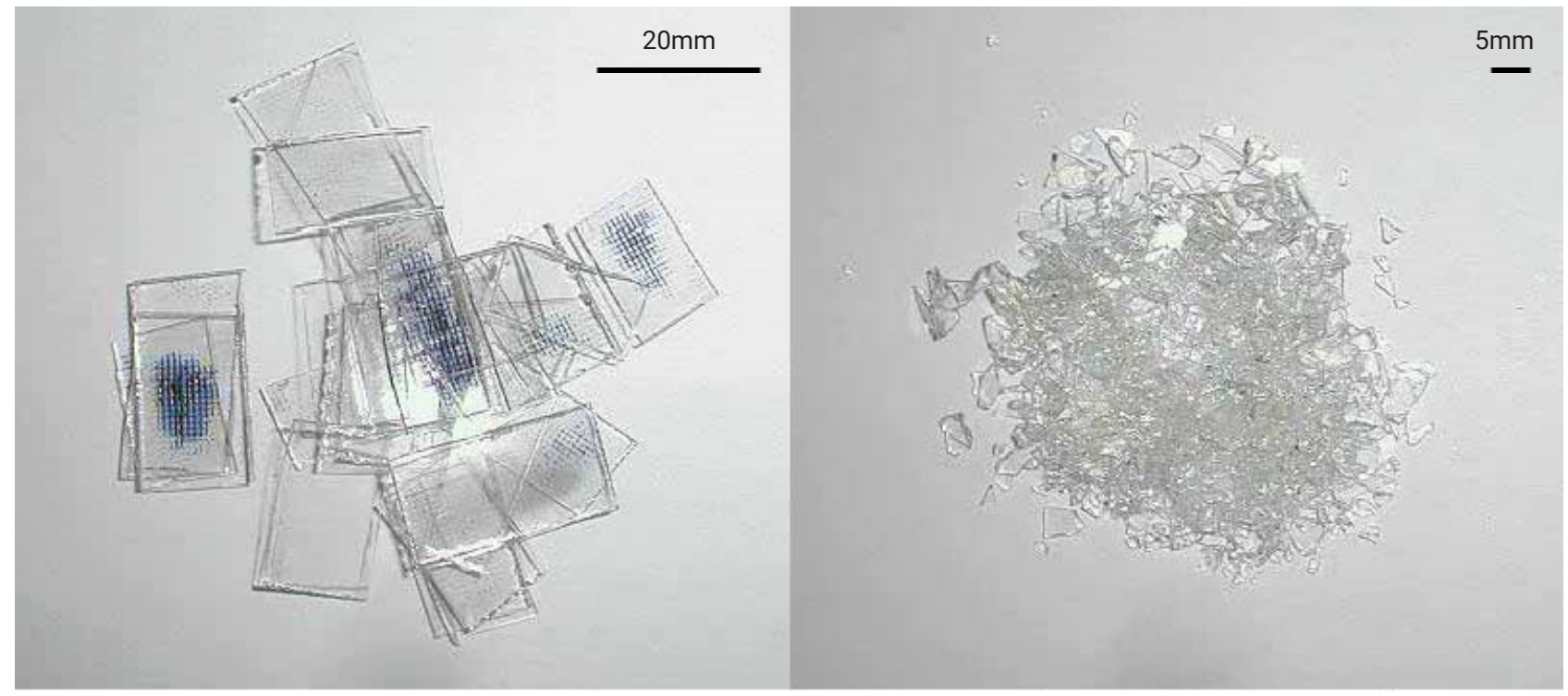

FIGURE 9: . The effect of glass size on the remaining color of glass after sub-CW treatment of $\mathrm{CF}$ glass with $0.1 \mathrm{M}$ NaOH solution. Reaction time and temperature were $5 \mathrm{~min}$ and $180^{\circ} \mathrm{C}$, respectively. 
TABLE 1: Effect of treated CF glass size on tin recoveries when they were treated with sub-CW added $0.1 \mathrm{M} \mathrm{NaOH}$ at $180^{\circ} \mathrm{C}$ for $5 \mathrm{~min}$.

\begin{tabular}{c|c} 
Treated CF glass size & Tin Recovery [\%] \\
\hline $5 \mathrm{~mm}$ & 92 \\
\hline $5-10 \mathrm{~mm}$ & 92 \\
\hline $20 \mathrm{~mm}$ & 90 \\
\hline$\ldots \ldots$
\end{tabular}

ment was carried out using $0.1 \mathrm{M} \mathrm{NaOH}$ at $180^{\circ} \mathrm{C}$ for $5 \mathrm{~min}$. The recovery of tin $\eta_{S n}$ in the $5 \mathrm{~mm}$ and $5-10 \mathrm{~mm}$ CF glasses were $92 \%$, just slightly $2 \%$ higher than the $20-\mathrm{mm}$ sized CF glass. Since the smaller $5 \mathrm{~mm}$ sized CF glass gave only $2 \%$ better recovery of tin than the larger $20 \mathrm{~mm}$-sized CF glass, the effect of tin recovery is not significant. Thus, glass breaking process would be sufficient enough than crushing process since breaking process might require less energy consumption .

In this study, high purity glass substrates were recovered from CF glass, in addition to tin. The glasses are superior value substrate products because it combines Corning's fusion process and optical melting technology for its production. The glass substrates recovered from CF glass by sub-CW has smooth surface and transparent, therefore require no repolishing upon reuse. Thus, by recovery of tin and glass substrates simultaneously, it is certain that the sub-CW technology is highly economical. Furthermore, tin is readily separated just by filtration. This could probably lead to the lowest operational cost compared to the other methods that require chemical post-treatments to separate and treat the chemical residues after the recovery.

\section{CONCLUSIONS}

The recovery of tin and high-quality glass substrate from LCD panel waste was technically feasible by $\mathrm{NaOH}$ added sub-CW treatment. Detail conclusions are given as follows:

1. Treatment for 5 min using sub-critical water without $\mathrm{NaOH}$ added showed a maximum of $80 \%$ and $6 \%$ tin recovery from $\mathrm{CF}$ glass and TFT glass, respectively. However, when $\mathrm{NaOH}$ was added $(0.1 \mathrm{~N}), 95 \%$ of both CF glass at $160^{\circ} \mathrm{C}$ and TFT glasses at $220^{\circ} \mathrm{C}$ was recovered. More, tin did not dissolve in the liquid-phase but was appended with the organic multilayers. The multilayers were removed together from the CF and TFT glasses. This phenomenon is very beneficial because tin in the form of ITO was readily separated from CF and TFT glasses, and easily recuperated on the filter.
2. The reaction temperature $160-180^{\circ} \mathrm{C}$ in $\mathrm{CF}$ glass and $220^{\circ} \mathrm{C}$ in TFT glass, $\mathrm{NaOH}$ concentration $0.05-0.1 \mathrm{~N}$, and reaction time 5-15 min were enough to get maximum recovery of $\operatorname{tin}(\eta=91-95 \%)$.

More tin was recovered, and the glass substrate became completely clean and transparent when sub-CW treatment was performed on smaller glass size $(5 \mathrm{~mm})$.

\section{REFERENCES}

Alfantazi, A.M., Moskalyk, R.R., 2003. Processing of indium: A review. Miner. Eng. 16, 687-694.

Fortes, M.C.B., Martins, A.H., Benedetto, J.S., 2003. Indium recovery from acidic aqueous solutions by solvent extraction with D2EHPA: A statistical approach to the experimental design. Braz. J. Chem. Eng. 20, 121-128.

Gabriel, A.P., Giordani, B.B., Kasper, A., Veit, H.M., 2017. Indium Extraction From LCD Screens, in: 16th International Waste Management and Landfill Symposium. CISA Publisher, 2-6 October 2017, Sardinia, Italy.

Gabriel, A.P., Giordani, B.B., Kasper, A., Veit, H.M., 2017. LCD Screens - Indium Leaching in: 16th International Waste Management and Landfill Symposium. CISA Publisher, 2-6 October 2017, Sardinia, Italy.

Honma, T., Muratani, T., 2005. Material Collection from Liquid Crystal Display Wasted Panels. Sharp Technical Journal 92, 17-22.

Hsieh, S.J., Chen, C.C., Say, W.C., 2009. Process for recovery of indium from ITO scraps and metallurgic microstructures. Mat. Sci. and Eng.: B 158, 82-87.

Kulkarni, A.K., Daneshvarhosseini, S., Yoshida, H., 2011. Effective recovery of pure aluminum from waste composite laminates by sub- and super-critical water. J. Supercrit. Fluids 55, 992-997.

Lee, J.H., Liu, D.N., Wu, S.T., 2008. Introduction to flat panel displays, in: A. Lowe, M. Kriss (Eds.), WID Series in Display Technology, Wiley, United Kingdom, 57-103.

Li, J., Gao, S., Duan, H., Liu, L., 2009. Recovery of valuable materials from waste liquid crystal display panel. Waste Manag. 29, 20332039.

Li, Y., Liu, Z., Li, Q., Liu, Z., Zeng, L., 2011. Recovery of indium from used indium-tin oxide (ITO) targets. Hydrometallurgy 105, 207-212.

Park, K.S., Sato, W., Grause, G., Kameda, T., Yoshioka, T., 2009. Recovery of indium from In203 and liquid crystal display powder via a chloride volatilization process using polyvinyl chloride. Thermochimica Acta 493, 105-108.

Ueberschaar, M., Schlummer, M., Jalalpoor, D., Kaup, N. and Rotter, V.S., 2017. Potential and Recycling Strategies for LCD Panelsfrom WEEE. Recycling 2, 7.

Wolfgang, W., Kretzschmar, H.J. (2008). International Steam Tables: Properties of Water and Steam Based on the Industrial Formulation IAPWS-IF97. Berlin Heidelberg: Springer-Verlag

Yoshida, H., Izhar, S., Nishio, E., Utsumi, Y., Kakimori, N., Feridoun S.A. 2014. Recovery of indium from TFT and CF glasses in LCD panel wastes using sub-critical water. Sol. Energy Mater. Sol. Cells 125, 14-19.

Yoshida, H., Izhar, S., Nishio, E., Utsumi, Y., Kakimori, N., Feridoun, S.A., 2015. Recovery of indium from TFT and CF glasses of LCD wastes using $\mathrm{NaOH}$-enhanced sub-critical water. J. Supercrit. Fluids 104, 40-48. 